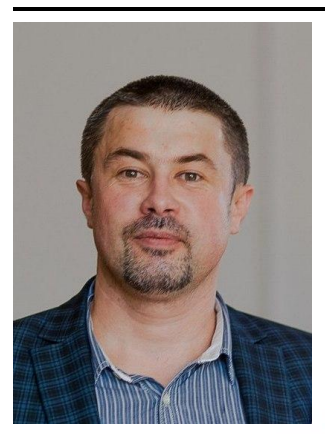

УДК 631.15:636(476)

https://doi.org/10.47612/978-985-7149-55-1-2020-46-49

Александр Горбатовский, заведующий сектором экономики

отраслей сельского хозяйства

Институт системных исследований в АПК НАН Беларуси, г. Минск

\title{
Методические подходы к разработке прогнозов развития и планированию эффективной интенсисрикации скотоводства
}

Основанный на самоокупаемости и самофинансировании аграрный бизнес предполагает повышение конкурентоспособности сельскохозяйственной продукции, насыщение внутреннего продовольственного рынка, расширение экспортных возможностей агропромышленного комплекса. Указанные приоритеты аграрной политики требуют реализации мероприятий по укреплению производственно-технического и трудового потенциала, структурных преобразований и устойчивого функционирования отраслей АПК [3]. В данной связи актуализируется необходимость оценки факторов обеспечения динамичного развития, а также разработки методических подходов к прогнозированию эффективного функционирования отраслей животноводства.

Анализ развития животноводства показал, что за 2015-2019 гг. в хозяйствах всех категорий Республики Беларусь наблюдалось увеличение объемов производства молока и реализации скота и птицы на убой (в живом весе) на 4,9 и 3,8 \% соответственно. При этом отмечено падение объемов реализации КРС на убой на 7,3 \%, что в общих объемах компенсируется за счет роста продаж свинины $(+2,5 \%)$ и других видов мяса $(+8,6 \%)$ [5].

Исследованиями установлено, что на развитие животноводства в данный период влияли:

устаревание технологий производства и недостаток техники;

несформированность или отсутствие полноценной кормовой базы;

низкий уровень диверсификации производства, квалификации персонала;

отсутствие эффективной схемы организации производства, системной стратегии развития и реформирования организаций.

Серьезной проблемой для большинства сельскохозяйственных организаций является сверхнормативное использование ресурсов и их недостаточная окупаемость продукцией. Прежде всего это касается кормовых ресурсов, их качественной составляющей, сбалансированности по основным нормируемым питательным веществам. Так, в 2019 г. в мясном скотоводстве перерасход кормов составил $37,3 \%$, а при производстве молока $-3,7 \%$, что ниже показателей 2015 г. на 1,8 и 4,4 п. П. соответственно. Резервы производства молока и мяса КРС в рамках сельскохозяйственных организаций Республики Беларусь за счет сбалансированного уровня кормления в 2019 г. исчисляются на уровне 295 (для четырех областей, исключение составляют Брестская и Гродненская) и 140 тыс. т соответственно, что выражается в недополучении совокупной выручки в размере 415 млн руб.

7 Результаты комплексного изучения состояния отраслей мясного и молочного скотоводства, в том числе выявленные тенденции и проблемы, установленные резервы и перспективные направления, нами предлагается принять за основу при разработке прогнозов устойчивого функционирования отраслей. Принципы, на которых строится научное обоснование темпов дальнейшего развития, должны соответствовать современным приоритетам государства, агропромышленного комплекса в целом и животноводства в частности, в том числе возможностям ресурсного обеспечения, пропорциональности развития отраслей животноводства и степени их адаптивности к внешним факторам конкурентной среды.

Сущность методических подходов прогнозирования развития отраслей скотоводства состоит в разработке практических процедур согласованного прогнозирования ключевых параметров развития и планирования эффективной интенсификации, предполагающих следующие результаты:

- разработка стратегии развития кормовой базы для различных уровней (сельскохозяйственных организаций, регионов, республики) на базе установленных резервов эффективности использования кормовых ресурсов;

- обоснование структуры и себестоимости кормов, их объемов для обеспечения параметров производства и роста эффективности (уровень кормления, затраты на корма в структуре материально-денежных затрат в расчете на голову, обеспечивающие меры и направления и др.);

- прогнозирование численности по категориям работников: обслуживающих молочное поголовье; доярок; обслуживающих молодняк и взрослый скот на откорме;

- обоснование производительности труда, включая характеристики напряженности использования живого труда и нормы обслуживания животных, и роста заработной платы, источников ее формирования (затраты на оплату труда с начислениями в структуре материально-денежных затрат в расчете на голову, обеспечивающие меры и направления и др.);

- определение экономических параметров и индикаторов согласованного развития отраслей скотоводства и кормопроизводства, включая расчетные уровни себестоимости, товарности продукции, производительности труда и рентабельности продаж. 
В рамках выработки методических подходов по разработке прогнозов предложены направления развития отраслей скотоводства и производства в сельскохозяйственных организациях. Апробация выполнена на примере молочного скотоводства Витебской области и включает экономические расчеты, подтверждающие эффективность выполненных прогнозов.

Проведенная оценка состояния отрасли показала необходимость применения сквозного подхода, суть которого заключается в продвижении от стратегических направлений обеспечения целевых объемов производства до внедрения конкретных мер технологического и организационно-экономического характера, планирования производственно-экономических показателей развития. Осуществление предлагаемого подхода в процессе прогнозирования базируется на алгоритме, включающем этапы:

- обоснования резервов наращивания продуктивности животных (методика установления резервов роста производства молока и мяса КРС, денежной выручки от реализации за счет нормированного кормления);

- выявления резервов эффективности использования кормовых ресурсов и разработки стратегии развития кормовой базы (в разрезе регионов республики, выделенных групп сельскохозяйственных организаций различного уровня технологического развития производства);

- анализа динамики трудовых ресурсов и прогноза численности работников отрасли (включая характеристики напряженности их труда, его производительности и оплаты);

- обоснования роста заработной платы и источников ее формирования (в увязке с производительностью труда и за счет дополнительных объемов денежной выручки, прибыли от реализации продукции);

- планирования натуральных и стоимостных параметров развития.
Поэтапная разработка вариантного прогноза показала, что на основании установленных резервов роста производства молока и получения прироста КРС за счет обеспечения нормативной конверсии кормов и использования сбалансированных рационов кормления (табл. 1), оценки в разрезе основных групп кормов (травянистые и концентрированные) уровня эффективности их использования (табл. 2) может быть обоснована стратегия развития кормовой базы с учетом региональной специфики отрасли. Применительно к условиям Витебской области ее направлениями должны стать:

- обеспечение нормативного уровня кормления животных под планируемый уровень продуктивности. (Справочно. Фактический перерасход кормов при производстве молока - 7 \%, в том числе травянистых $16 \%$; при получении привесов КРС-50\%, в том числе травянистых кормов - $69 \%$ );

- балансирование в рационах соотношения грубых и сочных кормов;

- обеспечение нормативных параметров ввода концентратов в рационы коров и КРС на выращивании и откорме (при фактической доле 18,5 и 14,1\% должен быть обеспечен норматив не менее 25 и $24 \%$ coответственно).

Прогноз численности работников отрасли (рис.) выполнен на основании фактических данных по двум вариантам: оптимистичному и пессимистичному. После нормирования коэффициентов регрессии трендов до единицы определено взвешенное прогнозное (на 2021 г.) значение показателя по категориям работников. Так, ожидается снижение количества работников, обслуживающих молочное стадо коров, на $7 \%$, доярок - на $5 \%$.

В рамках совершенствования порядка планирования и последующего контроля целевых параметров производства молока и получения продукции выращивания

Таблица 1. Резервы производства продукции и получения денежной выручки в сельскохозяйственных организациях Витебской области

\begin{tabular}{|c|c|c|c|c|c|c|c|}
\hline \multirow{3}{*}{$\begin{array}{l}\text { Молочное направление } \\
\text { КРС (вид продукции) }\end{array}$} & \multirow{3}{*}{$\begin{array}{c}\text { Фактическая } \\
\text { продуктивность } \\
\text { животных }\end{array}$} & \multirow{2}{*}{\multicolumn{2}{|c|}{$\begin{array}{c}\text { Уровень кормления, } \\
\text { ц к. ед/гол. }\end{array}$}} & \multirow{3}{*}{$\begin{array}{c}\text { Отклонение фак- } \\
\text { тического уровня } \\
\text { кормления от } \\
\text { нормативного, \% }\end{array}$} & \multicolumn{3}{|c|}{ Дополнительно получено } \\
\hline & & & & & \multicolumn{2}{|c|}{ продукции на } & \multirow{2}{*}{$\begin{array}{c}\text { денежной } \\
\text { выручки - } \\
\text { всего, } \\
\text { млн руб. }\end{array}$} \\
\hline & & фактичес & нормативный & & голову & $\begin{array}{l}\text { все поголо- } \\
\text { вье, тыс. т }\end{array}$ & \\
\hline $\begin{array}{l}\text { Основное стадо молочно- } \\
\text { го скота (молоко) }\end{array}$ & 3609 кг/год & 43,09 & 40,27 & 7,0 & -412 кг & -6 & $-40,6$ \\
\hline $\begin{array}{l}\text { Животные на выращива- } \\
\text { нии и откорме (продукция } \\
\text { выращивания КРС) }\end{array}$ & 452 г/сутки & 22,21 & 14,86 & $7=\begin{array}{r}49,5 \\
-6\end{array}$ & $-95 \Gamma$ & & $-56,0$ \\
\hline
\end{tabular}

Примечание. Таблицы 1, 2 составлены автором на основе собственных расчетов по данным сводного годового отчета Витебской области за 2019 г. и [1].

Таблица 2. Оценка отклонения фактических уровней кормления крупного рогатого скота от соответствующих нормативных в сельскохозяйственных организациях Витебской области

\begin{tabular}{|c|c|c|c|c|c|c|}
\hline \multirow{4}{*}{ Группа животных } & \multicolumn{6}{|c|}{ Фактический перерасход (с «минусом» - экономия) кормов относительно нормативного уровня } \\
\hline & \multicolumn{2}{|c|}{ всего } & \multicolumn{4}{|c|}{ в том числе } \\
\hline & \multirow{2}{*}{ ц к. ед/гол. } & \multirow{2}{*}{$\%$} & \multicolumn{2}{|c|}{ травянистых } & \multicolumn{2}{|c|}{ концентратов } \\
\hline & & & ц к. ед/гол. & $\%$ & ц к. ед/гол. & $\%$ \\
\hline $\begin{array}{l}\text { Основное стадо молочного } \\
\text { скота (коровы) }\end{array}$ & 2,82 & 7,00 & 4,91 & 16,26 & $-2,09$ & $-20,78$ \\
\hline $\begin{array}{l}\text { Животные на выращивании } \\
\text { и откорме }\end{array}$ & 7,35 & 49,46 & 7,79 & 69,01 & $-0,44$ & $-12,44$ \\
\hline
\end{tabular}




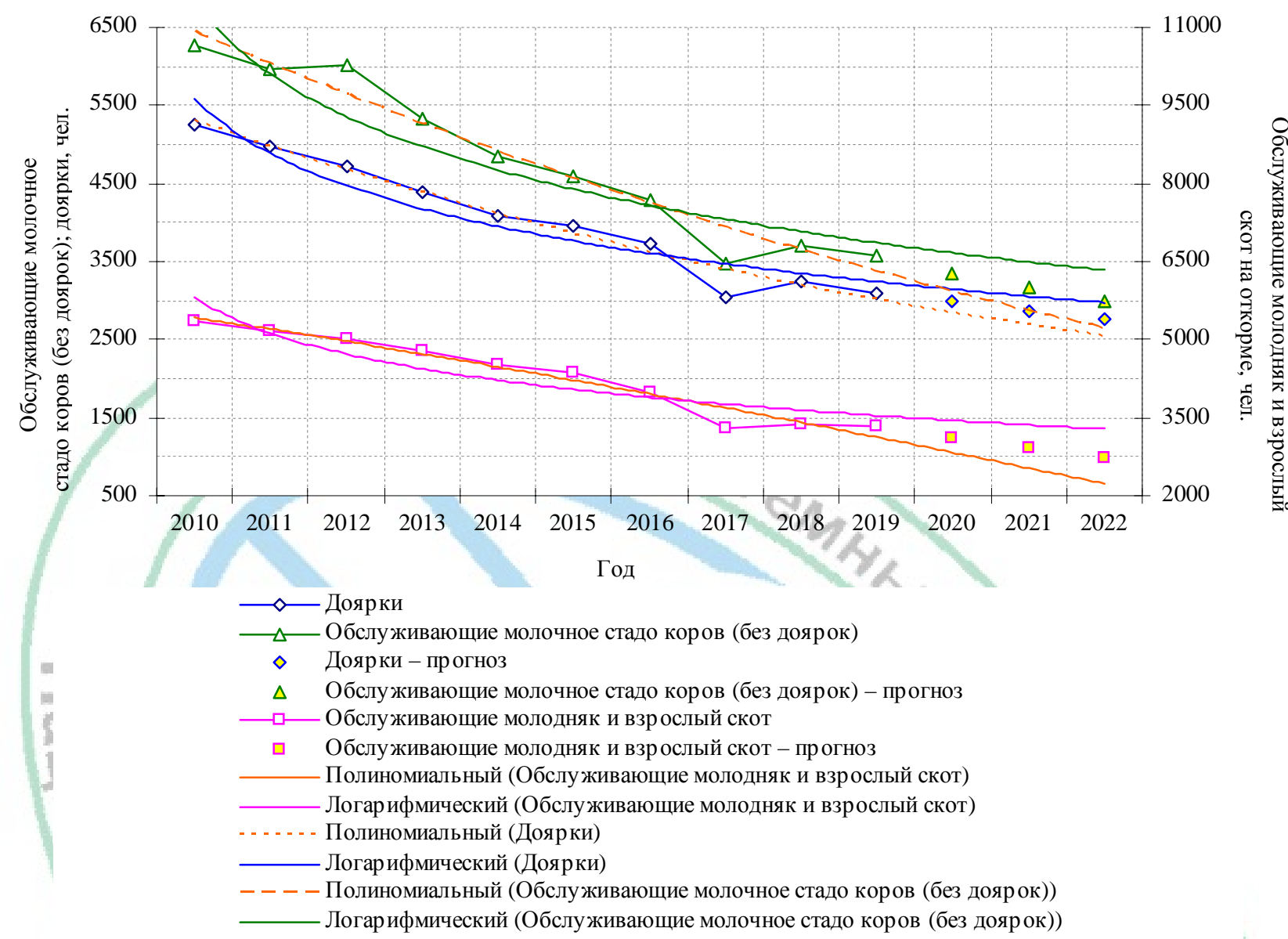

КРС рекомендуется расширить перечень показателей мониторинга эффективного развития отраслей скотоводства, приняв во внимание согласованное обеспечение таких показателей, как уровень кормления животных, доля концентратов в рационе, продуктивность, себестоимость произведенной продукции.

При условии сохранения численности поголовья коров и объемов производства на уровне базового года обеспеченный фонд заработной платы служит источником ее роста для коллектива работников. В зависимости от размеров полученной дополнительно денежной выручки может быть установлен размер дополнительной оплаты. В разрезе групп различного уровня технологического развития производства молока рекомендуется соотношение дополнительного фонда заработной платы устанавливать не выше 25-30 \% от размеров дополнительной денежной выручки от реализации молока.

Разработанные нами производственные и экономические параметры (табл. 3,4 ) свидетельствуют, что сбалансированное развитие кормопроизводства и молочного скотоводства предполагает увеличение удоя $(+11,3 \%)$ за счет наращивания в рационе объемов концентрированных кормов (+21\%) и оптимизации травянистых (прирост объемов производства всех видов кормов $1 \%$ ), повышение производительности живого труда $(+18,3 \%)$ и рост его оплаты (+22,6 \%), что обеспечит снижение себестоимости производства молока $(-11,2 \%)$, рост прибыли до $81 \%$ к фактическому ее объему, рентабельности продаж до 24,8 \% (+9,4 п. п.).

Таким образом, методические подходы по разработке прогнозов развития и планированию эффективной интенсификации в отраслях скотоводства включают обоснование применения сквозного подхода в процессе прогнозирования, совершенствование порядка планирования и перечня показателей мониторинга эффективного развития, параметры стимулирования производительности труда во взаимосвязи с ростом экономических результатов функционирования отраслей скотоводства; ориентированы на обеспечение конкурентоспособности продукции посредством сбалансированного и инновационного развития животноводства в контексте последовательной эффективной интенсификации и наращивания конкурентных преимуществ на основе ресурсосбережения, реализации потенциала продуктивности животных, роста производительности труда, сокращения материальных затрат и улучшения качества продукции.

Научная новизна разработанных подходов состоит в следующем:

- применяемый сквозной подход базируется на осуществлении ряда практических процедур согласованного 
Таблица 3. Прогнозируемые производственные параметры молочного скотоводства в сельскохозяйственных организациях Витебской области, 2021 г.

\begin{tabular}{|c|c|c|c|c|c|c|c|c|c|}
\hline \multirow{2}{*}{$\begin{array}{c}\text { Группа } \\
\text { продуктивности } \\
\text { коров, кг/гол. }\end{array}$} & \multicolumn{2}{|c|}{$\begin{array}{l}\text { Молочная продук- } \\
\text { тивность коров }\end{array}$} & \multicolumn{2}{|c|}{ Затраты кормов } & \multirow{2}{*}{$\begin{array}{c}\text { Доля концен- } \\
\text { тратов в раци- } \\
\text { оне (по норма- } \\
\text { тиву), \% }\end{array}$} & \multicolumn{2}{|c|}{$\begin{array}{c}\text { Расход } \\
\text { концентратов }\end{array}$} & \multicolumn{2}{|c|}{$\begin{array}{l}\text { Производитель- } \\
\text { ность } 1 \text { чел.-ч }\end{array}$} \\
\hline & кг/гол. & рост $^{1}$, раз & $\begin{array}{l}\text { ц к. ед/ } \\
\text { гол. }\end{array}$ & рост $^{1}$, раз & & $\begin{array}{c}\text { ц к. ед/ } \\
\text { гол. }\end{array}$ & рост $^{1}, \%$ & кг & $\begin{array}{c}\text { pocT }^{1}, \\
\text { ра3 }\end{array}$ \\
\hline ww - худиие из худиих & 2600 & 1,243 & 33,68 & 1,026 & 16,0 & 5,39 & $+51,8$ & 29,0 & 1,317 \\
\hline bw - лучшие из худших & 3800 & 1,180 & 42,75 & 1,008 & 20,0 & 8,55 & $+39,9$ & 34,6 & 1,261 \\
\hline wb-xудшие из лучших & 4800 & 1,066 & 50,49 & 1,002 & 26,0 & 13,13 & $+16,9$ & 41,0 & 1,163 \\
\hline bb-лучшие из лучших & 6900 & 1,006 & 60,78 & 1,003 & 35,5 & 21,58 & $+1,2$ & 64,3 & 1,024 \\
\hline По Витебской области & 4126 & 1,113 & $745,30^{2}$ & 1,010 & 23,8 & $177,06^{2}$ & $+20,8$ & 39,3 & 1,183 \\
\hline
\end{tabular}

Примечание. Таблицы 3,4 составлены автором на основе собственных расчетов, авторских подходов, данных годовых отчетов сельскохозяйственных организаций Витебской области.

${ }^{1}$ За базовый год приняты данные соответствующих показателей 2019 г.

${ }^{2}$ Суммарные значения показателей по области.

Таблица 4. Прогнозируемые экономические параметры молочного скотоводства в сельскохозяйственных организациях Витебской области, 2021 г.

\begin{tabular}{|c|c|c|c|c|c|c|c|c|}
\hline \multirow{2}{*}{$\begin{array}{l}\text { Группа продуктивности } \\
\text { коров, кг/гол. }\end{array}$} & \multicolumn{2}{|c|}{$\begin{array}{c}\text { Себестоимость про- } \\
\text { изводства молока }\end{array}$} & \multicolumn{2}{|c|}{ Заработная плата } & \multicolumn{2}{|c|}{$\begin{array}{l}\text { Дополнительный } \\
\text { объем, млн руб. }\end{array}$} & \multirow{2}{*}{$\begin{array}{l}\text { Соотношение } \\
\text { дополнитель- } \\
\text { ных зарплаты } \\
\text { и выручки, \% }\end{array}$} & \multirow{2}{*}{$\begin{array}{l}\text { Рентабель- } \\
\text { ность продаж, } \\
\%\end{array}$} \\
\hline & руб/т & $\operatorname{pocr}^{1}, \%$ & руб/мес. & $\begin{array}{l}\text { рост }^{1} \text { на } \\
1 \text { чел.-ч, раз }\end{array}$ & выручки & $\begin{array}{c}\text { фонда } \\
\text { зарплаты }\end{array}$ & & \\
\hline ww-худшие из худших & 443,3 & $-17,1$ & 520 & 1,237 & 14,66 & 1,88 & 12,8 & 21,2 \\
\hline bw-лучшие из худших & 416,6 & $-15,5$ & 655 & 1,233 & 20,76 & $3,13=$ & 15,1 & 25,1 \\
\hline 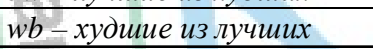 & 443,8 & $-9,1$ & 750 & 1,282 & 5,87 & 1,37 & 23,4 & 23,7 \\
\hline bb-лучшие из лучших & 495,5 & $-4,9$ & 900 & 1,138 & 0,73 & 0,22 & 29,6 & 27,8 \\
\hline По Витебской области & 449,9 & $-11,2$ & 680 & 1,226 & 42,03 & 6,59 & 15,7 & 24,8 \\
\hline
\end{tabular}

За базовый год приняты данные соответствующих показателей 2019 г.

прогнозирования в рамках этапов аналитических и конструктивных расчетов. Его суть заключается в разработке технологических и организационно-экономических мер, обеспечивающих достижение обоснованных целевых параметров прогноза;

- порядок планирования развития отраслей скотоводства и перечень показателей мониторинга его эффективности предложено совершенствовать путем включения и посредством сбалансированного обеспечения показателей уровня кормления и продуктивности животных, доли концентратов в рационе и себестоимости произведенной продукции;

- для целей стимулирования производительности труда предложено направлять до 25-30 \% от объемов дополнительной (за счет роста объемов продаж в результате реализации мер интенсификации производства) выручки на формирование фонда заработной платы, что будет эффективным источником обеспечения роста заработной платы и увязано с экономическими результатами функционирования отраслей (рост выручки и рентабельности продаж).

\section{Список использованных источников}

1. Бречко, Я. Н. Справочник нормативов трудовых и материальных затрат для ведения сельскохозяйственного производства / Я. Н. Бречко, М. Е. Сумонов; под ред. В. Г. Гусакова. - Минск : Белорус. наука, 2006. - 711 с.

2. Горбатовский, А. В. Теоретические и методические подходы к оценке конкурентоспособности продукции животноводства в условиях инновационного развития АПК / А. В. Горбатовский, О. Н. Горбатовская, В. В. Шварацкий // Проблемы повышения эффективности функционирования АПК: вопросы теории и методологии / под ред. В. Г. Гусакова. - Минск : Ин-т систем. исслед. в АПК НАН Беларуси, 2016. - С. 87-97.

3. Государственная программа развития аграрного бизнеса в Республике Беларусь на 2016-2020 годы [Электронный ресурс] : утв. постановлением Совета Министров Респ. Беларусь, 11 марта 2016 г., №196 (ред. от 09.07.2019 г. № 458) // КонсультантПлюс. Беларусь / ООО «ЮрСпектр», Нац. центр правовой информ. Респ. Беларусь. - Минск, 2019.

4. Научные системы ведения сельского хозяйства Республики Беларусь / В. Г. Гусаков [и др.] ; редкол.: В. Г. Гусаков (гл. ред.) [и др.] / Нац. акад. наук Беларуси, М-во сельского хоз-ва и прод. Респ. Беларусь. - Минск : Беларус. навука, 2020. -683 с.

5. Национальный статистический комитет Республики Беларусь [Электронный ресурс]. - Режим доступа: http://www.belstat.gov.by/. - Дата доступа: 12.09.2020. 